\title{
Development of biodegradable polyesterurethane membranes with different surface morphologies for the culture of osteoblasts
}

\author{
Jyh-Horng Wang, ${ }^{1}$ Chun-Hsu Yao, ${ }^{2}$ Wen-Yuan Chuang, ${ }^{3}$ Tai-Horng Young ${ }^{3}$ \\ ${ }^{1}$ Department of Orthopedic surgery, National Taiwan University Hospital, Taipei 10016, Taiwan, Republic of China \\ ${ }^{2}$ Department of Radiological Technology, Chungtai Institute of Health Sciences and Technology, Taichung, \\ Taiwan, Republic of China \\ ${ }^{3}$ Institute of Biomedical Engineering, College of Medicine and College of Engineering, National Taiwan University, \\ Taipei 10016, Taiwan, Republic of China
}

Received 15 March 1999; revised 15 October 1999; accepted 9 February 2000

\begin{abstract}
To evaluate the biocompatibility of biodegradable polyesterurethane membranes with different surface morphologies for their possible use as orthopedic biomaterials, rat osteoblasts were cultured on smooth, sunken, and particulate polyesterurethane membranes. A close interaction between cells and exposed particles on the particulate membranes was found. Cells on the particulate surfaces were well spread and flattened and had the greatest adhesion while cells on the smooth surfaces were more rounded, less spread, and less adhered. In addition, in order to investigate their in vivo degradation rates, the morphologic changes in retrieved membranes from 2,4 , and 8 weeks after subcutaneous implantation were observed by scanning electron microscopy and their average molecular weight changes were determined by gel permeation chromatography. These analyses showed that smooth membranes, com-
\end{abstract}

pared with the two other surface membrane types, had the greatest rate and degree of molecular weight change. In contrast, the molecular weight of particulate membranes, which favor the osteoblast culture, had not changed significantly at 8 weeks postimplantation. Thus particulate polyesterurethane membrane surfaces may be of use as an orthopedic biomaterial, and polyesterurethane membranes certainly provide an ideal system for further study of the relative contributions to biocompatibility and degradation derived from surface morphology. (c) 2000 John Wiley \& Sons, Inc. J Biomed Mater Res, 51, 761-770, 2000.

Key words: polyesterurethane membranes; osteoblasts; biodegradation; surface properties

\section{INTRODUCTION}

Polyurethanes are used widely in biomedical applications due to their good physical and mechanical properties together with their fairly good biocompatibility and antithrombogenicity characteristics. ${ }^{1}$ The purpose of this study was to evaluate the use of polyurethanes relative to the application of orthopedic devices. $^{2}$ Both the biocompatibility and degradation of biomaterials is of importance in biomedical materials research, and in this work polyesterurethanes were synthesized due to their degradability. ${ }^{3,4}$ Although

Correspondence to: T.-H. Young; e-mail: thyoung@ha.mc. ntu.edu.tw

Contract grant sponsor: Research Fund of Chinese Petroleum Company, administered by the National Science Council of the Republic of China

(c) 2000 John Wiley \& Sons, Inc. specific requirements will differ according to the nature of an application, a successful orthopedic implant requires a surface that not only is nontoxic but also allows the phenomenologic behavior of bone cells. ${ }^{5-7}$ Therefore, the evaluation of cell responses to a biomaterial's surface may be important in determining the capacity of a given material employed in a clinical situation. For example, bone cells can be exposed to different biomaterial surfaces if biomaterials are used in the fixation of orthopedic implants by allowing bone tissues to grow into the textured surface of implants. Accordingly, a characteristic of a biomaterial surface, such as surface morphology, may perturb the local environment and influence cell behavior. ${ }^{8-10}$ Likewise the degradation rate of a biomaterial also may be affected by variation in the morphology of a surface that comes into direct contact with host tissue. Thus if a proper relationship among the surface characteristics of an orthopedic implant, cell behavior, and degradation rate is to be established, implants must be 
designed with specific surfaces that will aid in a host's natural healing processes.

In this study we have evaluated in vitro osteoblast responses to polyesterurethane membranes with smooth, sunken, and particulate surface morphologies. The attachment of osteoblasts was assessed by scanning electron microscopy (SEM) and a Neubauer hemocytometer. In addition, these prepared membranes were implanted subcutaneously into rats to investigate the degradation rate in vivo. After a varying number of weeks, these membranes were retrieved and dissolved in tetrahydrofuran, and the average molecular weight was determined by gel permeation chromatography. The surface morphologic changes observed by scanning electron microscopy also were discussed. The prepared membranes were found to have a great influence on cell behavior and degradation rate in each case. In particular, the membrane with the particulate surface had the greatest cell number adhesion, better cell spreading, and the lowest degradation rate. This study clarifies the influence that the surface morphology of a biomaterial has on cell behavior and degradation rate when the surface of a biomaterial directly interfaces with the biologic environment.

\section{MATERIALS AND METHODS}

\section{Polymer synthesis}

Polyesterurethanes were synthesized by using a two-step polymerization method. Briefly, the first step involved the bulk polymerization of prepolymer by reacting 4, $4^{\prime}$ methylene diphenyl-diisocyanate (MDI; TCI, Tokyo, Japan) and poly(butylene adipate) diol with a molecular weight of 1000 (PBA 1000; Tai Chin, Taipei, Taiwan) at a mole ratio of 2:1 under a dried nitrogen system to prevent the reaction of the diisocyanate with moisture at $70^{\circ} \mathrm{C}$ for $1 \mathrm{~h}$. The prepolymer then was dissolved in dimethylformamide (DMF; Aldrich, Milwaukee, WI) to form a $50-w t \%$ prepolymer solution. In the second step, 1,4 butanediol (Aldrich, USA) as the chain-extender was added in an equimolar ratio with PBA 1000. The reaction was allowed to proceed at $70^{\circ} \mathrm{C}$ for $4 \mathrm{~h}$ until the isocyanate disappeared, which was confirmed by IR analysis. ${ }^{11}$ Its weight average molecular weight and polydispersity were calculated to be $34,600 \pm 1000$ and $1.5 \pm 0.2$ relative to polystyrene standards by gel permeation chromatography (GPC). Finally, the products were dissolved in DMF to form a 30-wt $\%$ polymer solution for the preparation of membranes.

\section{Membrane preparation and characterization}

Membranes were prepared by the dry process and the wet process of the phase inversion method. ${ }^{12}$ Polymer solution was cast on a glass plate in a uniform thickness of $200 \mu \mathrm{m}$ by an autocoater (KCC303, RK Print-Coat Instruments, UK) at $25^{\circ} \mathrm{C}$ for the preparation membranes. In this work, three polyesterurethane membranes were prepared by changing the phase inversion process, identified by the letters A, B, and $\mathrm{C}$, respectively. The casting solution was evaporated in a vacuum oven at $60^{\circ} \mathrm{C}$ for 2 days to obtain membrane $A$. Membranes $B$ and $C$ were prepared by immersing the casting solution immediately into a precipitation bath for $1 \mathrm{~h}$. The precipitation medium was 1-octanol and 1-pentanol for membranes B and C, respectively. After the evaporation or precipitation was completed, the formed membranes were thoroughly soaked in ethanol to remove any residual solvent and then extensively washed by water. Finally, the membranes were kept in a water bath at $25^{\circ} \mathrm{C}$ prior to membrane characterization or other experiments. The morphology of the membranes was examined using a scanning electron microscope (SEM). The freeze-dried samples were sputtered with gold and palladium in a vacuum using a Hitachi $\mathrm{S}-800$ microscope at $20 \mathrm{kV}$.

\section{Cell culture}

Rat osteoblasts enzymatically were isolated from neonatal rat calvaria following the method of Vrouwenvelder et al. ${ }^{13}$ Briefly, the calvaria of Wistar rats was excised, stripped of soft tissue, and washed three times in a phosphate buffer solution (PBS). Then it was digested in collagenase solution for $2 \mathrm{~h}$. The cells from the digestion were pooled, washed, resuspended in Dulbecco's modified Eagle medium (DMEM) supplemented with $10 \%$ fetal calf serum (GibcoRBL Life Technologies, Paisley, UK) and 1\% antibiotics (100 $\mathrm{U} / \mathrm{mL}$ of penicillin $\mathrm{G}$ sodium and $100 \mathrm{U} / \mathrm{mL}$ of streptomycin; Gibco-RBL Life Technologies, Paisley, UK), and then plated in plastic culture dishes.

Circular samples $15 \mathrm{~mm}$ in diameter were cut from the polyesterurethane membranes, rinsed extensively with distilled water, and sterilized under ultraviolet light overnight. They then were mounted in 24-well tissue culture plates (Corning, New York) by surgical adhesive CYNAL-5 (Nycomed Ingenor, France) to prevent them from floating. Subsequently, cell suspensions in DMEM medium were added to the membrane surface at a density of $1 \times 10^{5}$ cells per well. Cell cultures were maintained in a humidified atmosphere with $5 \% \mathrm{CO}_{2}$ at $37^{\circ} \mathrm{C}$.

For morphologic observation, the cells adhering to the membrane were washed with PBS after $6 \mathrm{~h}$ of incubation and then fixed with $2.5 \%$ glutaraldehyde in PBS for $1 \mathrm{~h}$ at $4^{\circ} \mathrm{C}$. After a thorough washing with PBS, the cells were dehydrated by graded ethanol changes and then critical-point dried. The cells together with the membranes then were gold-sputtered in vacuum and examined by SEM. Also, the number of cells $6 \mathrm{~h}$ and $24 \mathrm{~h}$ after cell seeding was measured. The membrane surface was washed with PBS twice to remove any cell debris present in the medium. Adhering cells were detached with trypsin, stained with trypan blue to determine cell viability, and counted using a Neubauer counting chamber under the inverted microscope. ${ }^{6}$ All experiments were repeated four times $(n=4)$. 


\section{Implantation and retrieval}

The aforementioned three different membranes were cut into disks of $1 \mathrm{~cm}$ in diameter and sterilized by suspension in $70 \%$ alcohol for $24 \mathrm{~h}$. Prior to implantation, the membranes were washed with sterile saline solution. Wistar rats were anesthetized with an intramuscular injection of a mixture of ketamine $(35 \mathrm{mg} / \mathrm{kg})$ and xylazine $(5 \mathrm{mg} / \mathrm{Kg})$ and prepared for surgery by shaving their backs and then scrubbing them with an alcohol solution. The membranes were implanted subcutaneously in the back of the rat. The animals were sacrificed at 2, 4, and 8 weeks postimplantation and the membranes retrieved from the animals. The retrieved membranes were washed in distilled water by sonication for 30 min to remove debris adhered to the surface and dried in vacuum for $24 \mathrm{~h}$. Membranes then were examined under SEM for ruptures and cracking and by GPC for changes in molecular weight.

\section{GPC analysis}

Implanted and nonimplanted (control) membranes were dissolved in tetrahydrofuran (THF) and analyzed by GPC using the PLgel 5- $\mu \mathrm{m}$ mixed-D column from Polymer Lab., UK. A sample concentration was $0.5 \%$ by weight with a 0.2-mL injection. Ultra-pure-grade THF (Alps Chem., Taiwan) was used as the mobile phase. The effluent flow rate was maintained at $1.0 \mathrm{~mL} / \mathrm{min}$ using a SPECTROFLOW 400 pump (Applied Biosystem Corporation, USA). The refractive index detector in this GPC system was a Shodex RI SE-61 (Showa Denko Corporation, Japan). The weight average molecular weight and the polydispersity were calculated from the measured retention time using calibration curves constructed from monodispersed polystyrene standards. Four animals were used per sample membrane $(n=4)$.

\section{Data analysis}

Data were presented as the mean \pm standard deviation. Statistical significance among the various membranes was calculated using one-way analysis of variance (ANOVA) followed by Student's $t$ test $(p<0.05$ was considered significant).

\section{RESULTS AND DISCUSSION}

\section{Membrane morphology}

The physical appearance of the prepared polyesterurethane membranes varied with different cast procedures. The direct evaporation of the cast polymer solution produced membrane A with a fairly dense and smooth structure, as indicated in Figure 1. The membrane retained the transparency feature of the cast solution film, indicating no phase separation of the cast film during membrane formation. In contrast, in preparing membrane $\mathrm{B}$, upon immersion in 1-octanol bath, the polymer film gradually developed a white opaque appearance. As shown in Figure 2, membrane $B$ consisted of a rough and sunken surface supported by a porous sublayer, indicating the coagulation process of the cast film involved liquid-liquid phase separation due to the exchange of solvent (DMF) and nonsolvent (1-octanol). The diameter of the sunken area was estimated as approximately a few micrometers. Macroscopically, membrane C, upon immersion in a 1-pentanol bath, also appeared opaque. However, Figure 3 shows that the pores on membrane $\mathrm{C}$ were smaller and the number of pores fewer than was the case on the sunken areas of membrane B. In addition, some uncommon particles of about micron order occur on the membrane surface to increase the surface roughness of membrane $\mathrm{C}$. With different circumstances, there can be two possible mechanisms for the formation of particles in membranes. The first possibility is that particles are generated by spinodal demixing. ${ }^{14}$ The second possible origin of particles is crystallization of polymer during the membrane formation process. ${ }^{15,16}$ Since the building particles on membrane $C$ are greater than the size of the nodules caused by the spinodal demixing, it is suggested that in this case polymer crystallization is responsible for the formation of particles.

In this study the osteoblast response and biodegradation of the prepared membranes with different surface morphologies were investigated. In addition to surface structure, the surface chemistry and crystallinity of membranes are very important factors affecting cell response and biodegradation rate. Although the hydrophobic segments and the hydrophilic segments are able to be selectively present at the surface in the course of preparation of the membrane, the nature of the precipitation medium has a great influence on the membrane surface chemistry. The hydrophobic components may migrate toward the surface at the moment the casting solution and the hydrophobic precipitation medium come into contact. Conversely, hydrophobic components are embedded into the deeper layer of the material. Likewise, the surface is enriched with hydrophobic components when membrane formation occurs in a dry state since the hydrophobic component has a lower interfacial free energy in air. Therefore the prepared membranes in this work had similar surface chemistry since the casting solution faced similar conditions (air, 1-octanol, and 1-pentanol), which was confirmed by underwater contact angle, attenuated total reflectance Fourier transform infrared spectroscopy, and X-ray photoelectron spectroscopy (data not shown). In addition, the prepared membranes also showed no significant difference in 


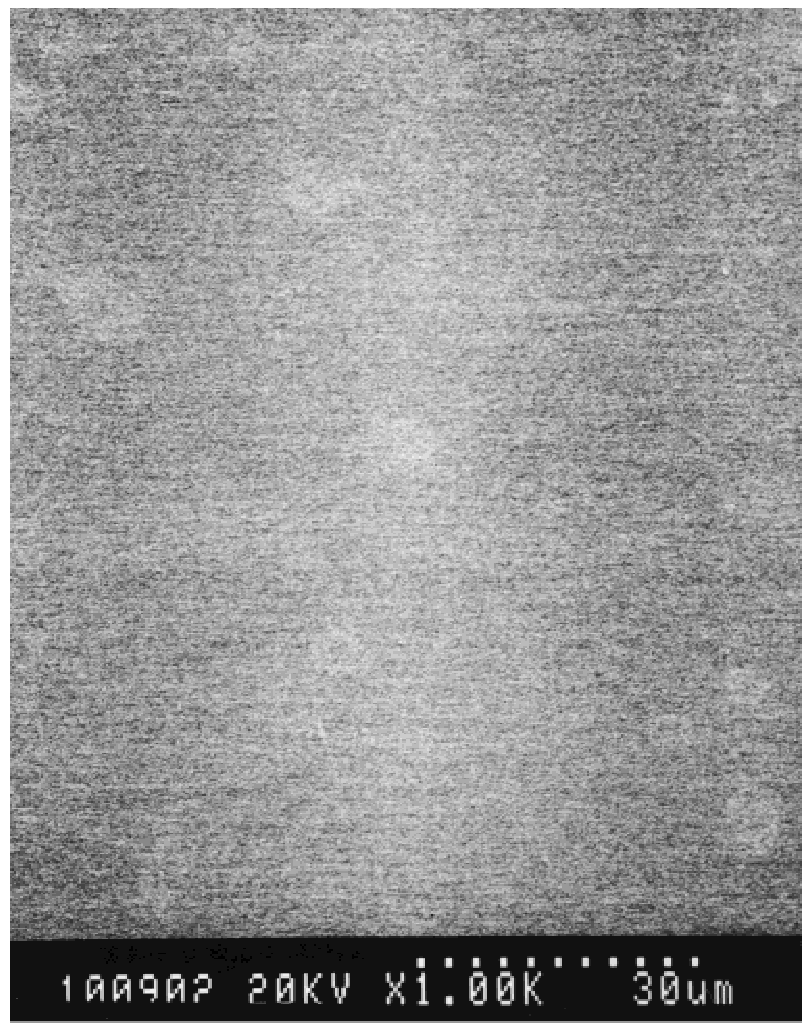

(a)
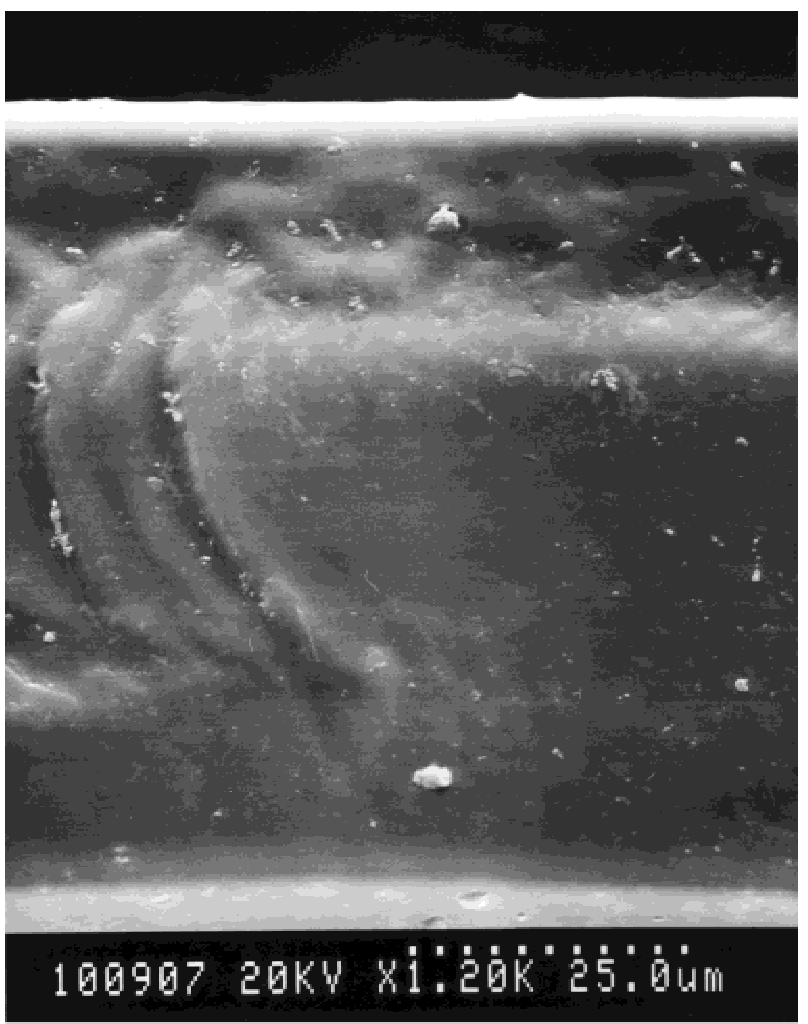

(b)

Figure 1. SEM photomicrographs of membrane A by direct evaporation of the cast polymer solution: (a) top surface; (b) cross section.

crystallinity, characterized by differential scanning calorimetry (data not shown). This can be explained in that even though liquid-liquid phase separation may dominate the membrane morphology, crystallization can appear in the membrane after liquid-liquid phase separation because the polymer-rich phase becomes supersaturated. Hence, the liquid-liquid demixed structure usually is followed and stabilized by crystallization. However, in this case, crystallization occurred only after cellular morphology was fixed. Crystallization, therefore, has only a small effect on the overall morphology of the formed membrane. On the other hand, if crystallization takes place prior to liquid-liquid phase separation during the membrane formation, polymer molecules may form particles on the membrane. Thus crystallinity of the polymer can be maintained in the membrane regardless of the sequence of phase transformations in the polymer solution. Overall, from this point forward the influence of the prepared membranes on cell behavior and the biodegradation rate is focused on the different membrane surface morphologies.

\section{Cell culture}

Cellular behavior on a biomaterial is an important factor in determining the biocompatibility of a bioma- terial. However, it is not possible to observe osteoblast cells on membranes B and C by using light microscopy due to poor optical transparency; therefore scanning electron micrographs of osteoblasts on the prepared membranes after culturing for $6 \mathrm{~h}$ were studied in order to observe cellular phenomenologic behavior. The whole process of adhesion and spreading consists of cell attachment, filopodial growth, cytoplasmic wedding, flattening of the cell mass, and ruffling of peripheral cytoplasm, all of which progresses in a sequential fashion. ${ }^{17}$ Figure 4 shows the morphology of osteoblasts cultured on the surface of membrane A. Osteoblasts cultured on this smooth surface appeared to have filopodia progressively extending centrifugally. At this time the cells still were spherical in appearance and the cells' surfaces appeared rough, with foldings, and showed somewhat inconspicuous microvilli-like projections. However, they were very conspicuous at the outside edge of the cell surface and extended out to make contact with the substrate, which is consistent with the situation expected for biocompatible polymers and indicates that polyesterurethane as a smooth structure does not provide a stimulus. Figure 5(a) shows the morphology of osteoblasts cultured on the surface of membrane B. Cells seem to have different morphologies at different locations. On top of the pore wall, the morphology of osteoblasts shows the same progressive stage as it did in 


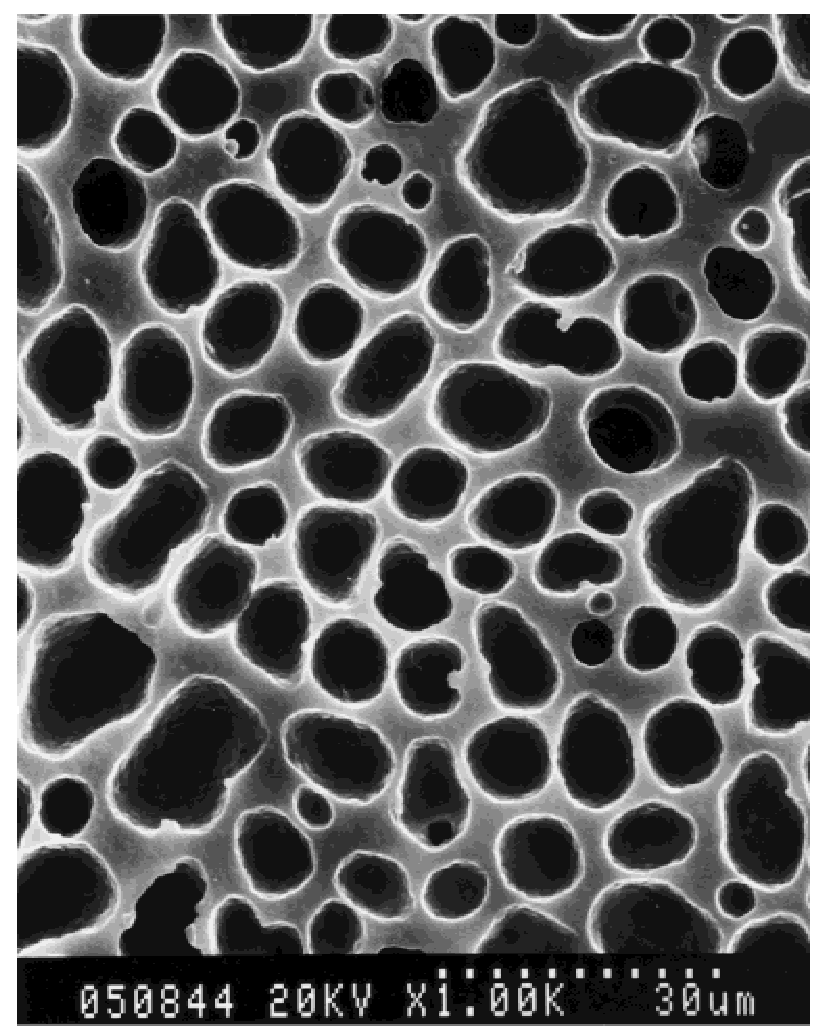

(a)

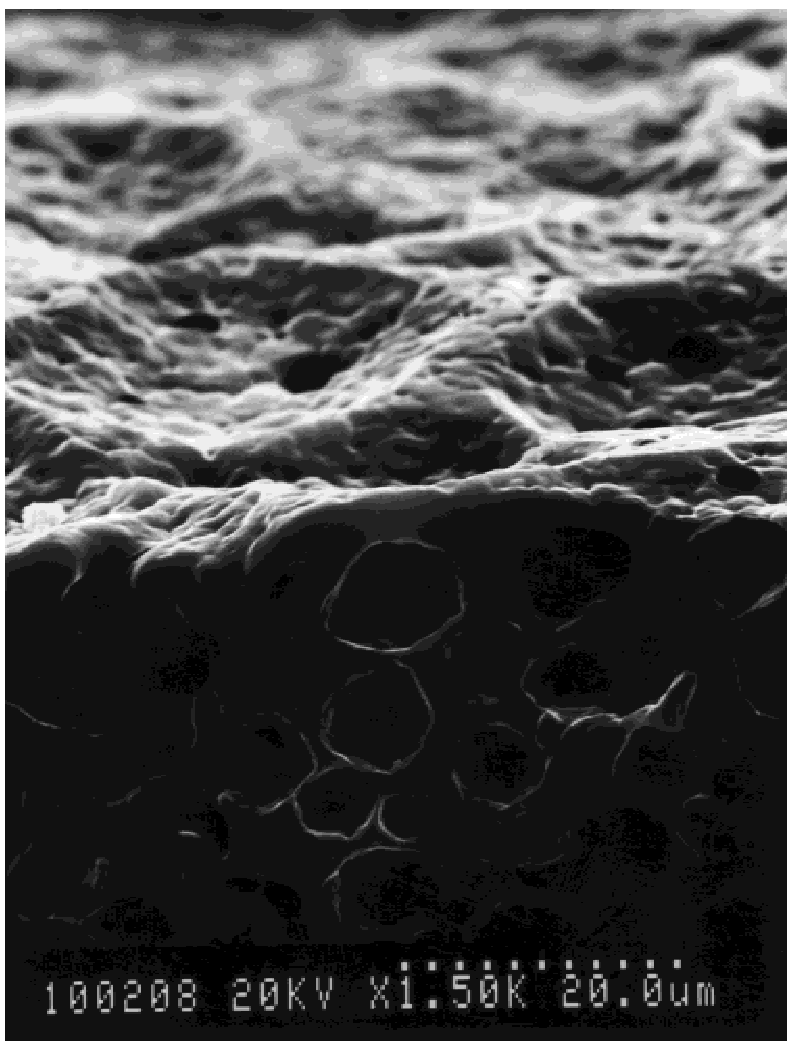

(b)

Figure 2. SEM photomicrographs of membrane B by immersion in 1-octanol bath: (a) top surface; (b) cross section near the top surface.

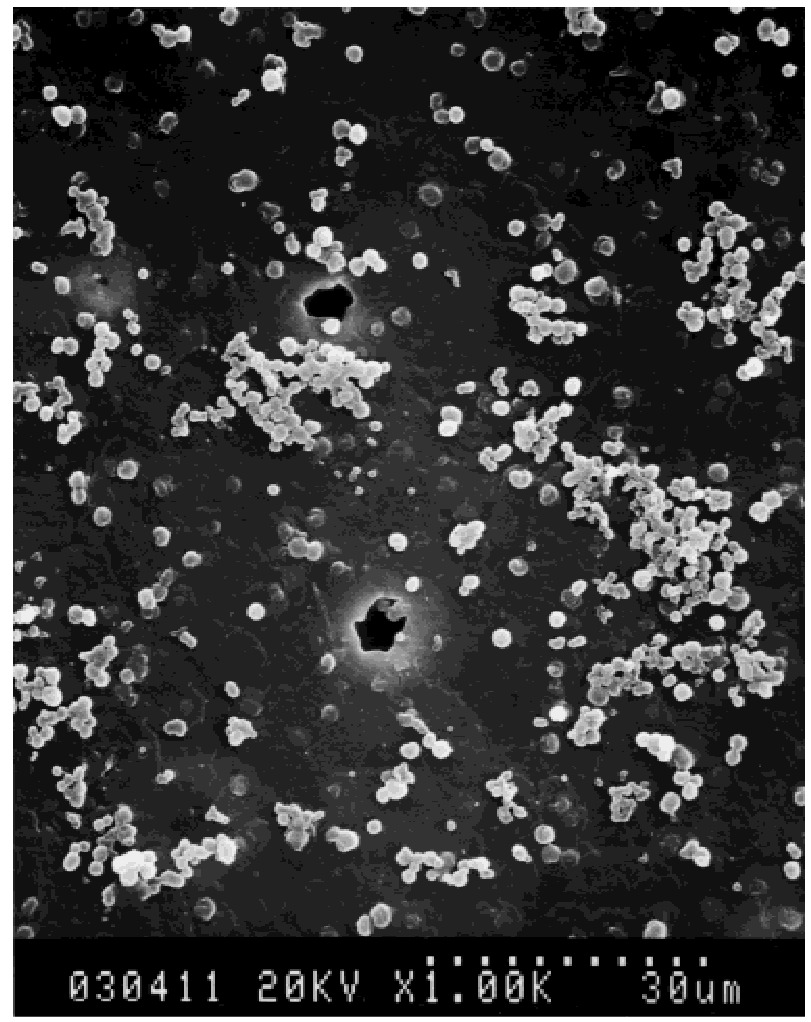

(a)

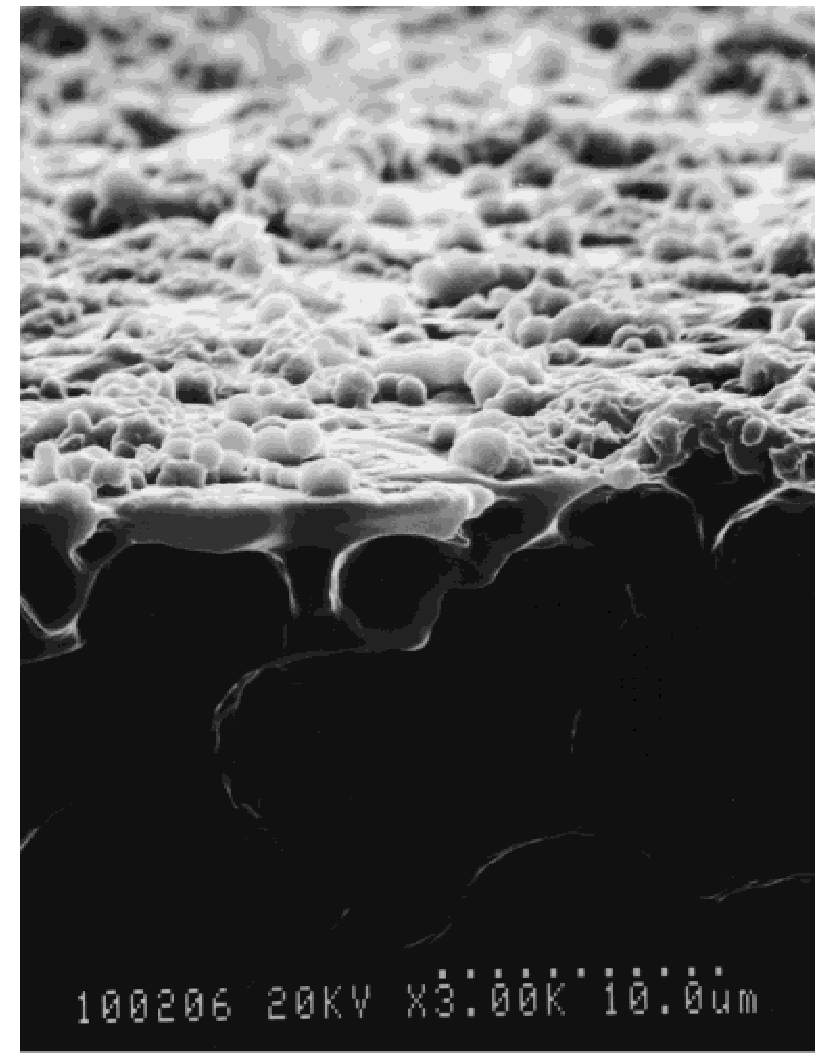

(b)

Figure 3. SEM photomicrographs of membrane $C$ by immersion in 1-pentanol bath: (a) top surface; (b) cross section near the top surface. 


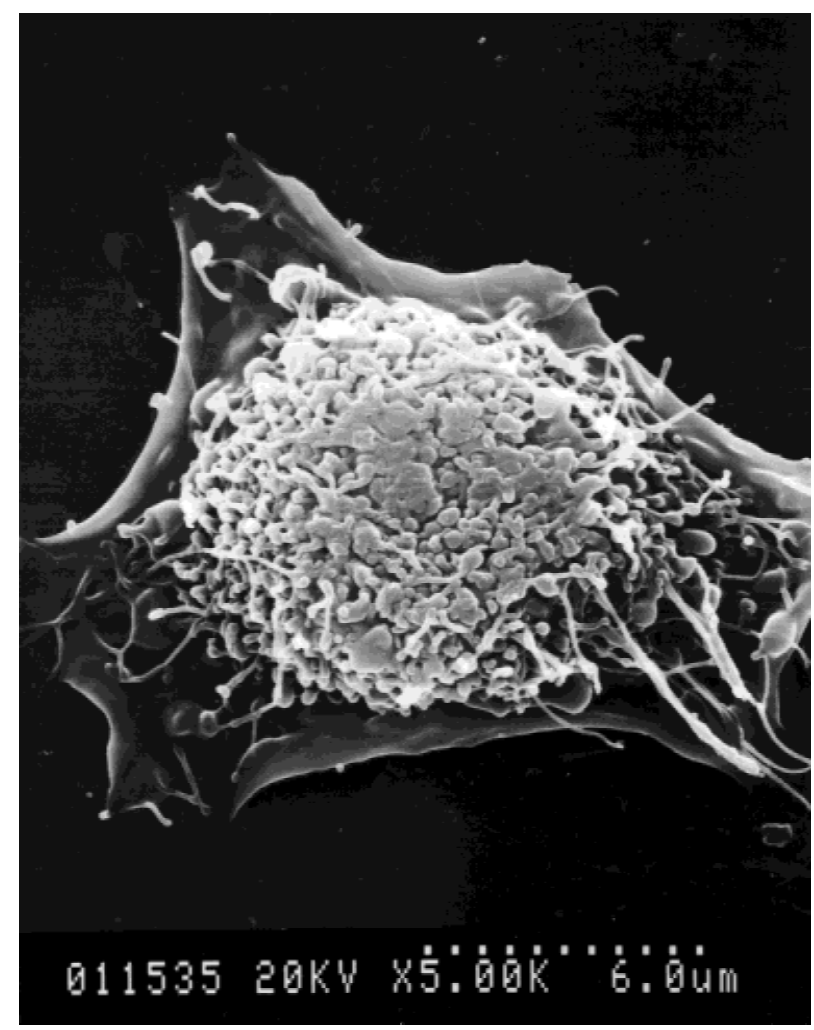

Figure 4. SEM photomicrographs of osteoblasts cultured on membrane A after $6 \mathrm{~h}$ in culture.

membrane A. At a higher magnification [Fig. 5(b)], it can be seen that the microvilli-like projections are formed over almost all of the cell surfaces, and filopodia progressively extend centrifugally from the numerous blebs. But cells located in the bottom of the pores show a poor morphology without filopodia [Fig. 5(c)]. This finding suggests that cell behavior is affected by any variation in a substrate's surface morphology. Figure 6 shows the morphology of osteoblasts attaching onto the surfaces of membrane C. SEM examination revealed that the osteoblasts with flattened morphology were in the stage of ruffling of peripheral cytoplasm and with intercellular contact. The results indicate that the conditions for membrane $C$ were better for the culturing of osteoblasts than they were for membranes A and B. Exactly what stimuli are responsible for the observed phenomenon remains to be determined. However, it is reasonable to attribute the difference in cell adhesion to the polyesterurethane membranes with different surface morphologies. It is interesting to contemplate whether or not the presence of particles on membrane $C$ stimulates the spreading of osteoblasts. Clearly, some direct influence of the surface particles on the osteoblasts must be involved as the cells on membrane $C$ were closely apposed to the surface of the membranes while those on membranes A and B retained rounded or restricted polar morphologies.

\section{Cell number counting}

Figure 7 shows the cell number of osteoblasts attached onto the various surfaces of polyesterurethane membranes after culturing for 6 and $24 \mathrm{~h}$. Surface morphology was found to influence cell attachment significantly. After $6 \mathrm{~h}$ of culture, there was a significant difference $(p<0.05)$ in the cell number on membranes $B$ and $C$ compared to the number of cells on membrane A. Although membrane B showed more cell adhesion than did A, SEM observation revealed that the cells were spread better on membrane A than were the cells in the bottom of the pores on membrane B. This suggests that cell adhesion might increase as the area of its contact with substratum increases; however, it does not promise that cells can spread very well. For membranes B and C, the results do not demonstrate any significant difference in the cell number after $6 \mathrm{~h}$ of culture. The surfaces of both membranes B and $C$ were rough, and an increase in the number of osteoblasts present on the surfaces with rough structure was observed. However, the surface was concave on the pores of membrane $B$ and convex on the particles of membrane $C$; therefore the greater number of cells and their better spreading and flattened appearance on the membrane $C$ probably were due to the exposed particles on the surface. This also suggests that osteoblasts are able to recognize the difference in substrate morphology and respond by altering their spreading degree. If so, these cells preferentially proliferating on the different membranes would be predictable. The results after $24 \mathrm{~h}$ of culture show the cells having grown on all the membranes but with same tendency as the cell growth after $6 \mathrm{~h}$; that is, the highest cell number was in membrane $C$ and the lowest was in the membrane A. From the analysis of the $t$ test, membrane A was regarded as significantly lower than the other two types of membranes $(p<0.05)$.

\section{GPC analysis}

Table I shows the weight average molecular weight and molecular weight distribution of retrieved membranes at 2, 4, and 8 weeks postimplantation. These data were compared with those of unimplanted membranes. Membrane A revealed significant reduction in weight average molecular weight at each implantation time and continuously decreased throughout the implantation period. The trend of the weight average molecular weight changes found in membrane A also was found in the case of membrane B. However, the degradation rate and degree were slower for membrane $B$ and less marked than those of membrane A. In contrast to membranes $\mathrm{A}$ and $\mathrm{B}$, no decrease trend in 


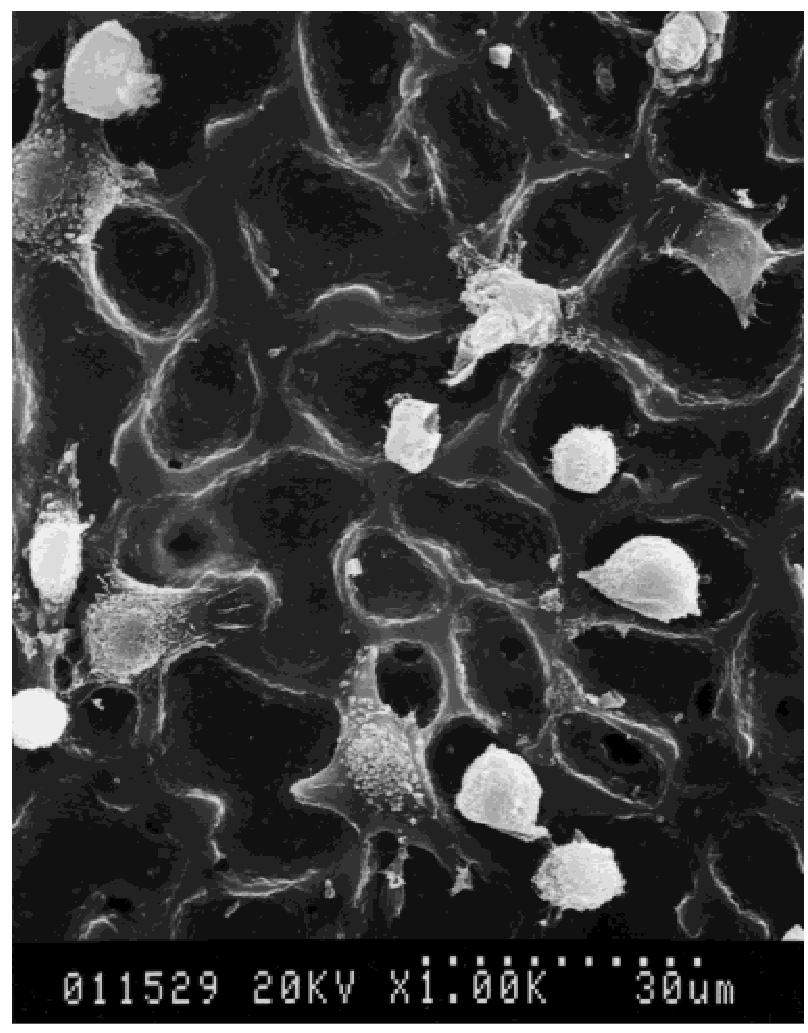

(a)

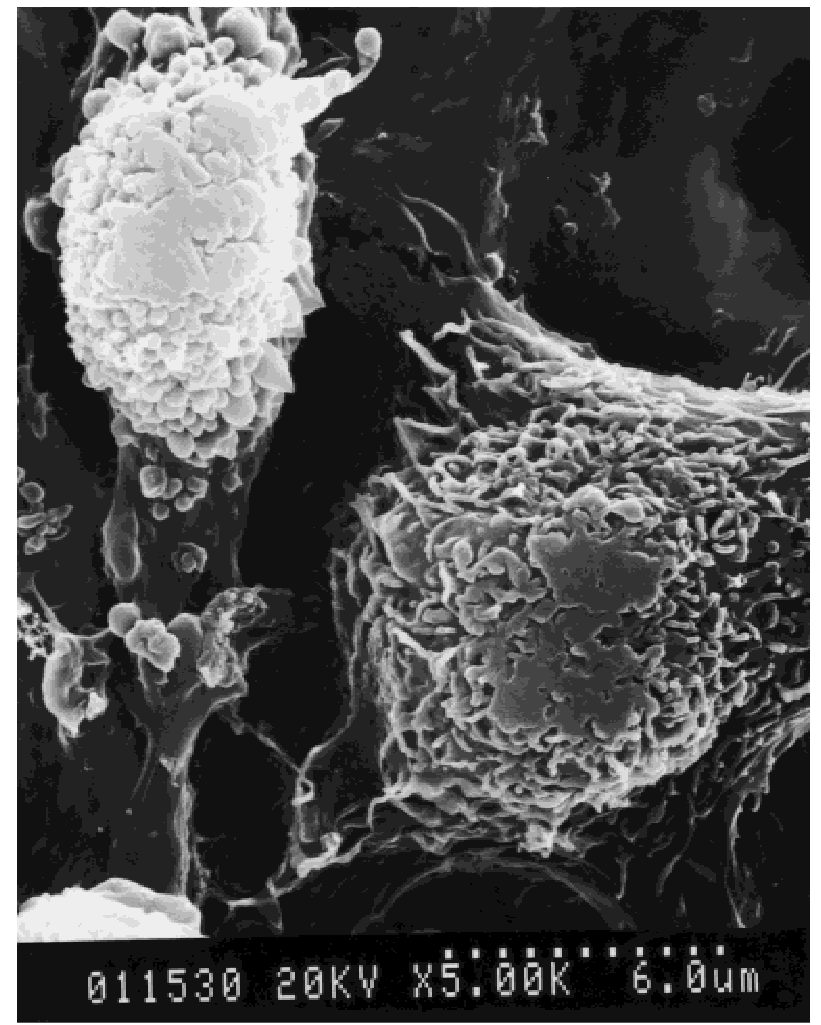

(b)

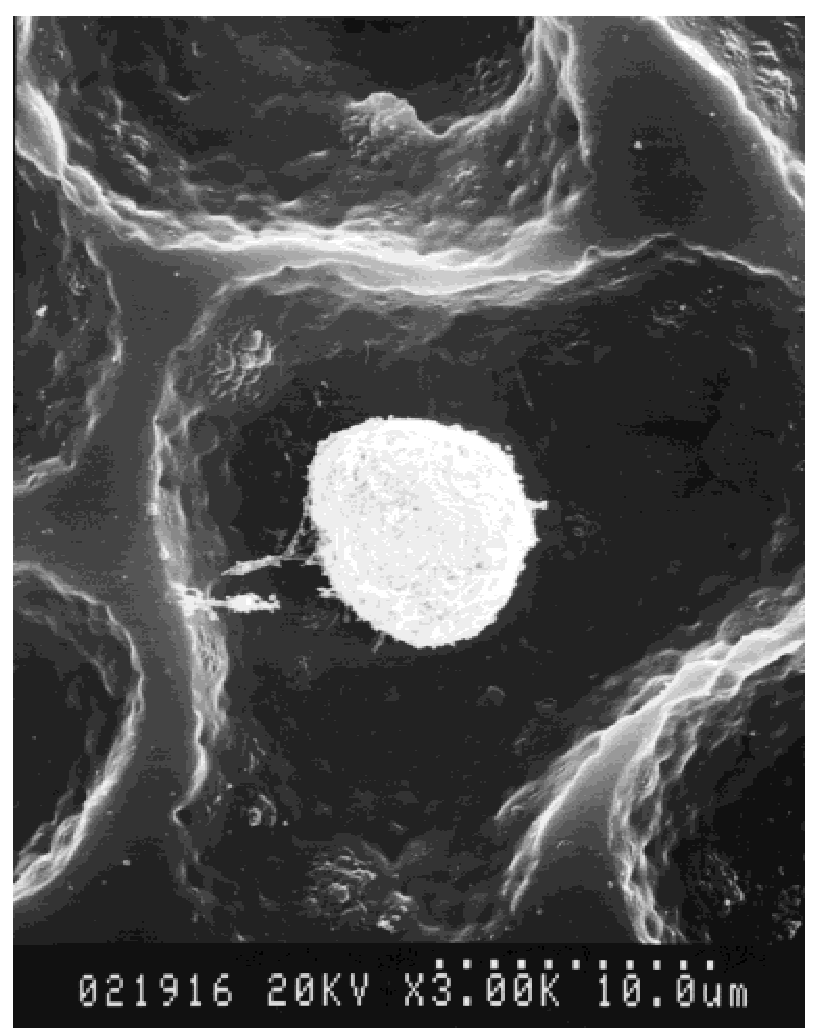

(c)

Figure 5. (a) SEM photomicrographs of osteoblasts cultured on membrane B after $6 \mathrm{~h}$ in culture; (b) the magnified photograph of (a) for the cell on top of the pore wall; (c) the magnified photograph of (a) for the cell in the bottom of the pore. 


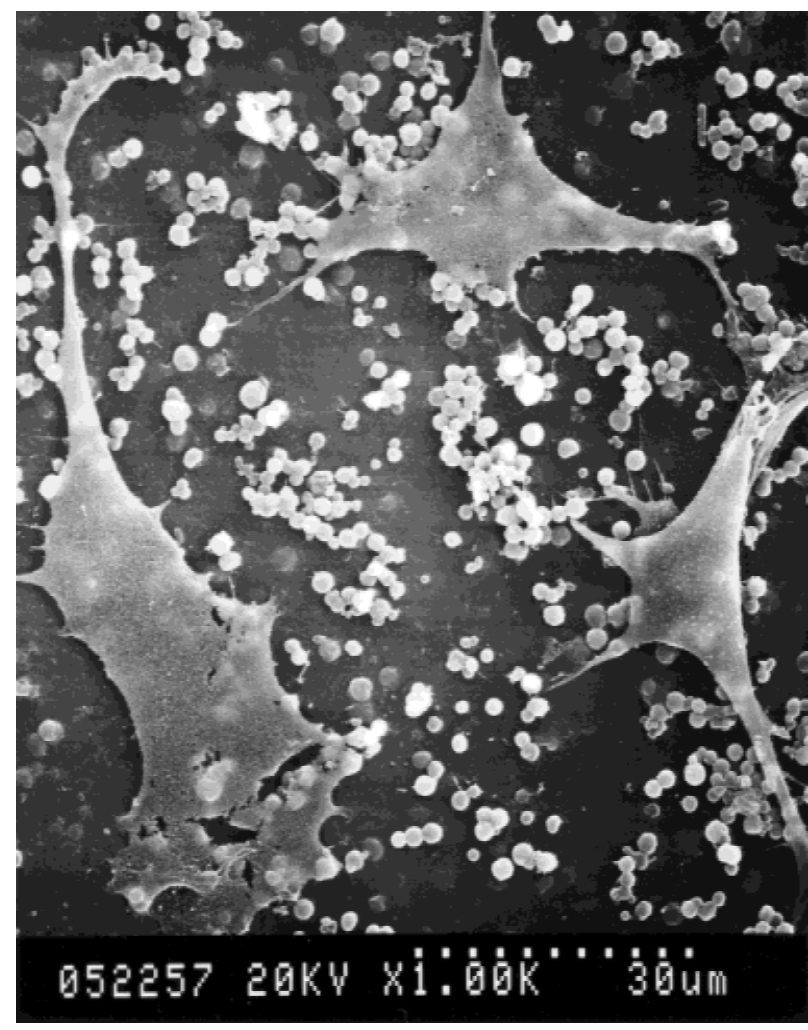

Figure 6. SEM photomicrographs of osteoblasts cultured on membrane $C$ after $6 \mathrm{~h}$ in culture.

weight average molecular weight was observed at the early stage of implantation in the case of membrane $C$. The average molecular weight of membrane $C$ was not significantly different from, and even was slightly greater than, the value of unimplanted membranes until after 4 weeks. In statistical analysis, this increase of the weight average molecular weight may be disregarded, but, based on the present results, degradation is greatly influenced by the surface structure of implants, which can be further examined by SEM (shown below).

SEM examination of degraded polyesterurethane membranes

Figure 8 shows the changes in surface morphology of polyesterurethane membranes. SEM micrographs

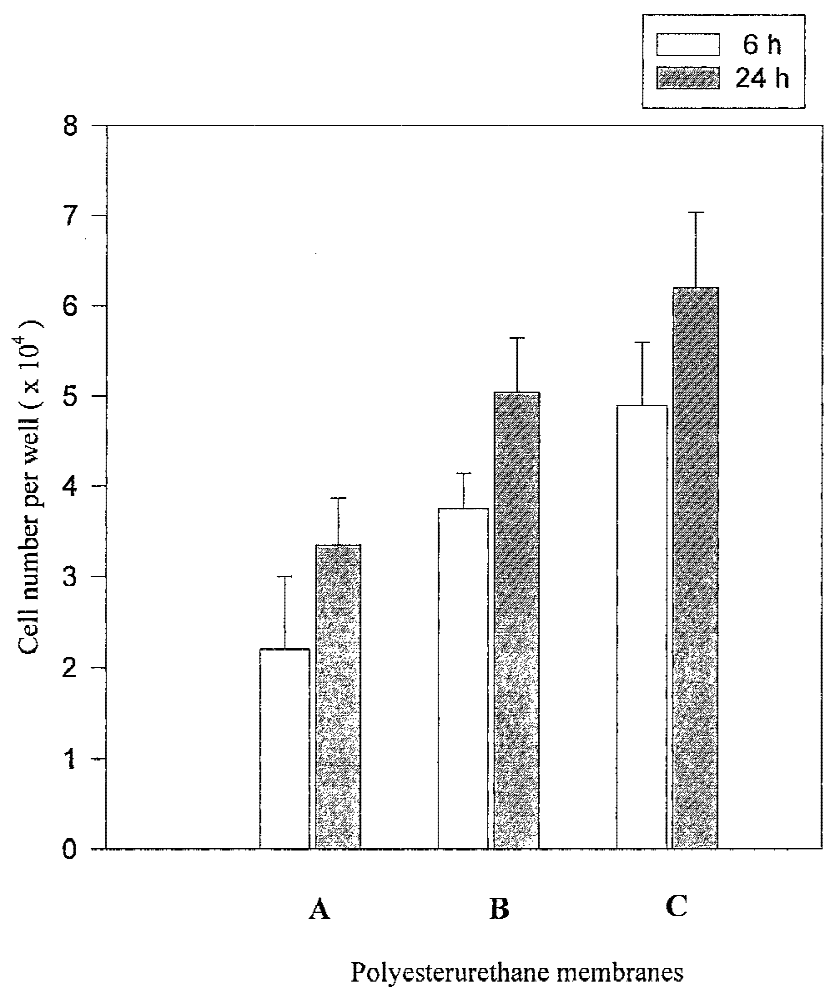

Figure 7. The number of osteoblasts on polyesterurethane membranes after 6 and $24 \mathrm{~h}$ culture. Sample numbers, $n=4$.

of polyesterurethane membranes before and after implantation reveal significant degradation in some but not all samples. Figure 8(a) shows large surface cracks and ruptures on membrane $A$ at 8 weeks postimplantation. Similar cracks also were observed on membrane B [Fig. 8 (b)] at the same implantation time. Although these cracks were smaller, the surface of membrane $B$ became wrinkled and rough. A comparison of membrane $C$ prior to implantation with membrane $C$ retrieved after 8 weeks [Fig. 8 (c)] showed only a small number of pits in a limited area on the implant. Although we have no idea how to explain the surface morphologic difference among membranes A, $B$, and $C$, degradation of a membrane obviously was affected by the membrane's surface morphology. Rough membranes seemingly can delay the degradation rate, especially if there are particles on the membrane's surfaces. This suggests that membrane A is not

TABLE I

Changes of the Weight Average Molecular Weight and Molecular Weight Distribution of Retrieved Membranes Compared with Those of Unimplanted Membranes

\begin{tabular}{|c|c|c|c|c|c|c|c|c|}
\hline \multirow[b]{2}{*}{ Membranes } & \multicolumn{2}{|c|}{ Unimplanted membranes } & \multicolumn{2}{|c|}{$2 \mathrm{wk}$} & \multicolumn{2}{|c|}{4 wk } & \multicolumn{2}{|c|}{$8 \mathrm{wk}$} \\
\hline & $\mathrm{Mw}^{*}$ & $\mathrm{MWD}^{+}$ & Mw & MWD & Mw & MWD & Mw & MWD \\
\hline A & $34,600 \pm 1000$ & $1.5 \pm 0.2$ & $31,200^{*} \pm 800$ & $2.6 \pm 0.3$ & $31,100^{\ddagger} \pm 1200$ & $2.7 \pm 0.3$ & $28,600^{\ddagger} \pm 900$ & $2.8 \pm 0.5$ \\
\hline B & & & $33,100 \pm 1500$ & $1.7 \pm 0.2$ & $33,100 \pm 1300$ & $1.9 \pm 0.3$ & $31,600^{\ddagger} \pm 1100$ & $2.0 \pm 0.4$ \\
\hline C & & & $37,000 \pm 700$ & $1.6 \pm 0.2$ & $35,400 \pm 1100$ & $1.7 \pm 0.2$ & $33,300 \pm 1000$ & $1.7 \pm 0.3$ \\
\hline
\end{tabular}

${ }^{*} \mathrm{Mw}$ : weight average molecular weight; ${ }^{\dagger} \mathrm{MWD}$ : molecular weight distribution. ${ }^{\ddagger}$ The data show a significant difference $(p$ $<0.05)$ compared to the unimplanted membranes. 


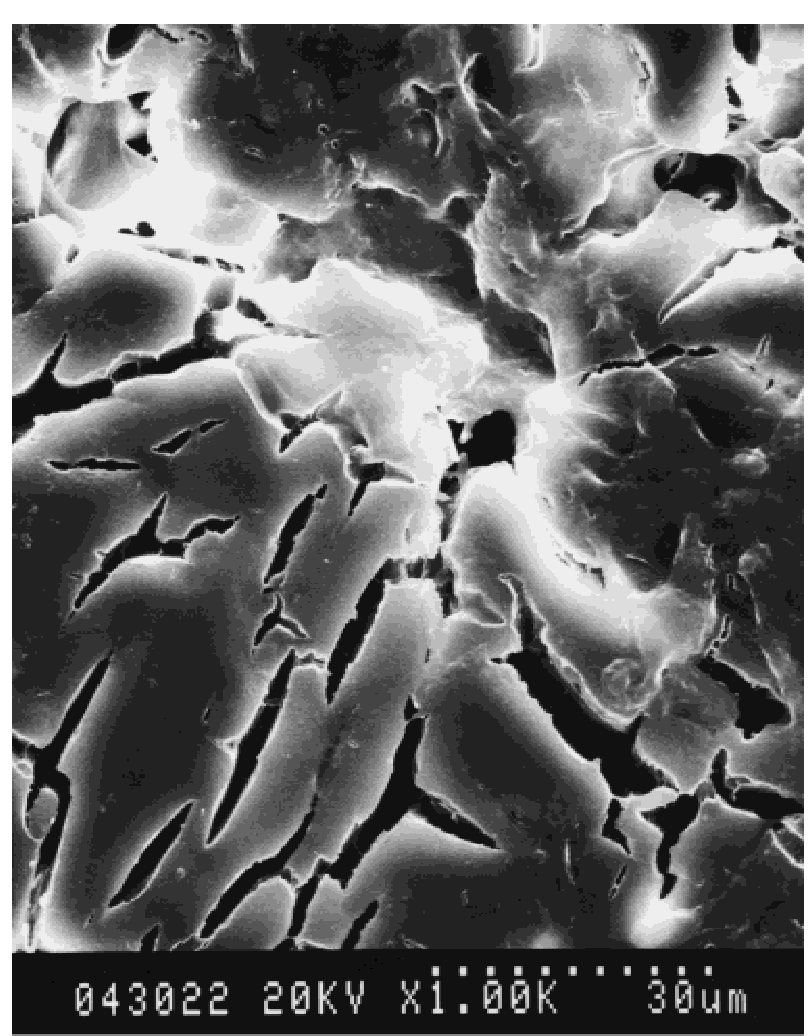

(a)

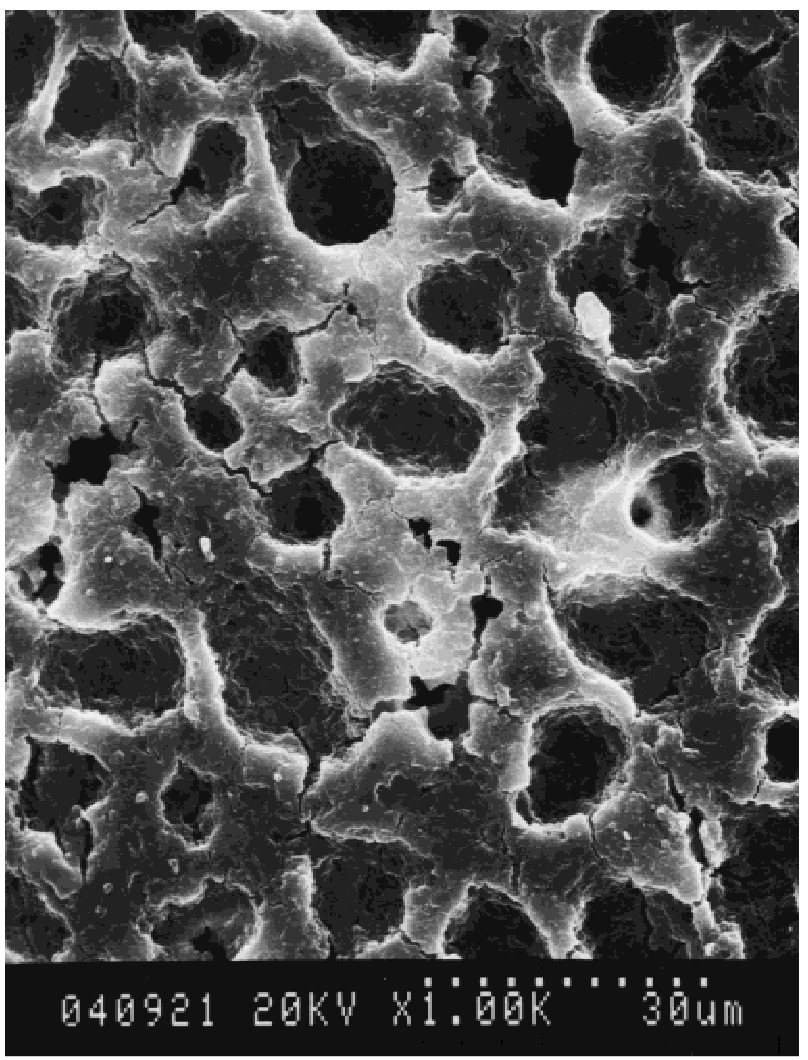

(b)

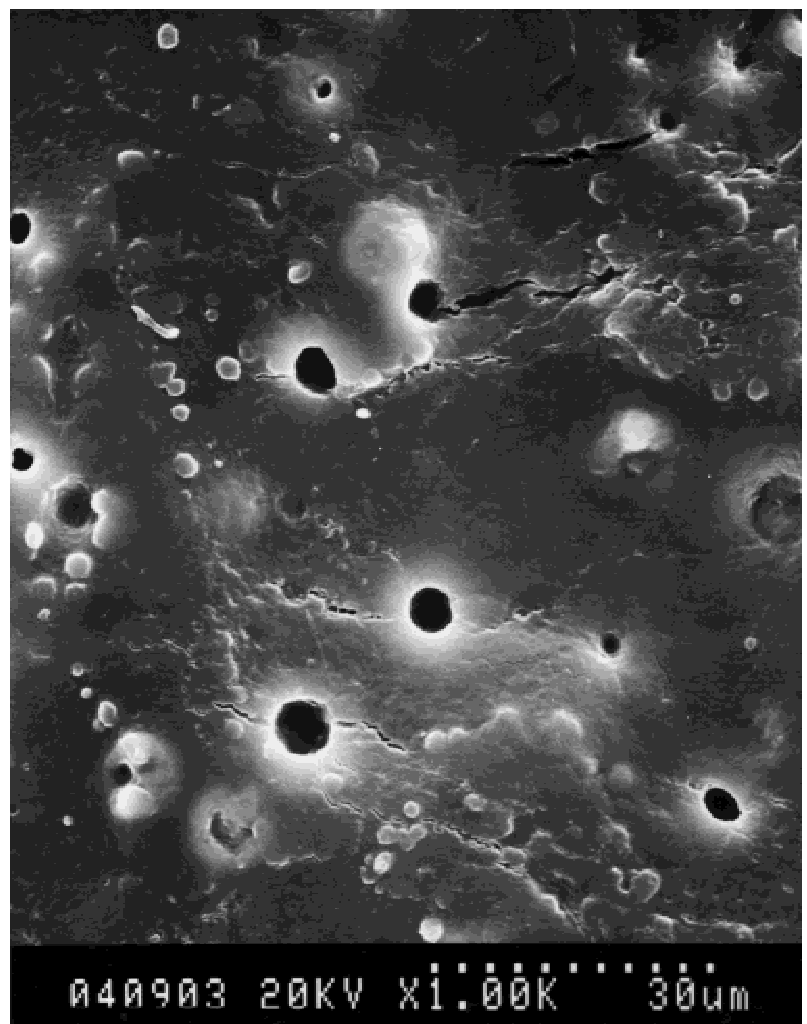

(c)

Figure 8. SEM photomicrographs of polyesterurethane membranes implanted for 8 weeks subcutaneously in rats: (a) membrane A; (b) membrane B; (c) membrane C. 
suitable in the repair of bone defects due to its relatively fast degradation during the early stage of healing.

\section{CONCLUSIONS}

In summary, polyesterurethane membranes with different surface morphologies showed different levels of osteoblast adhesion and different degradation rates. Membrane surface morphologies that determine the cell-material interaction may play an important role in the bone regeneration process. We found an especially close interaction between cells and exposed particles on membrane surfaces. Particulate surfaces reduced the degradation rate of membranes, but cells on particulate surfaces were well spread and flattened and had the greatest number. This work represents an initial step in understanding the relationship between cell behavior and substrate surface morphology. Ultimately it may be possible to improve on the design of orthopedic biomaterial surfaces currently in use by devising a surface that will enhance the boneproducing ability of cells that come into contact with it.

\section{References}

1. Lelah MD, Cooper SI. Polyurethane in medicine. Boca Raton, Florida: CRC Press; 1986. p. 35-71.

2. Warrer K, Karring T, Nyman S, Gogolewski S. Guided tissue regeneration using biodegradable membranes of polylactic acid or polyurethane. J Clin Periodontol 1992;19:633-640.

3. Saad B, Hirt TD, Uhlschmid GK, Neuenschwander P, Suter UW. Development of degradable polyesterurethanes for medical applications: In vitro and in vivo evaluations. J Biomed Mater Res 1997;36:65-74.
4. Rehman I, Andrews EH, Smith R. In vitro degradation of poly(ester-urethanes) for biomedical applications. J Mater Sci: Mater Med 1996;7:17-20.

5. Hunter A, Archer CW, Walker PS, Blunn GW. Attachment and proliferation of osteoblasts and fibroblasts on biomaterials for orthopedic use. Biomaterials 1995;14:287-295.

6. Bagambisa FB, Joos U. Preliminary studies on the phenomenological behaviour studies of osteoblasts cultured on hydroxyapatite ceramics. Biomaterials 1990;11:50-56.

7. Scotchford CA, Cascone MG, Downes S, Giusti P. Osteoblast responses to collagen-PVA bioartificial polymers in vitro: The effects of cross-linking method and collagen content. Biomaterials 1998;19:1-11.

8. Chesmel KD, Black J. Cellular response to chemical and morphological aspects of biomaterial surface. I. An in vitro model system. J Biomed Mater Res 1995;29:1089-1099.

9. Hoch HC, Staples RC, Whitehead B, Comeau J, Wolf ED. Signalling for growth orientation and cell differentiation by surface topography in Uromyces. Science 1987;235:1659-1662.

10. Young TH, Yao CH, Sun JS, Lai CP, Chen LW. The effect of morphology variety of EVAL membranes on the behavior of myoblasts in vitro. Biomaterials 1998;19:717-724.

11. Liao DC, Hsieh KH, Chern YC, Ho KS. Interpenetrating polymer networks of polyaniline and maleimide-terminated polyurethanes. Synth Meth 1997;87:61-67.

12. Kesting RE. Synthetic polymeric membranes. New York: John Wiley \& Sons, Inc.; 1985. p. 238-261.

13. Vrouwenvelder WCA, Groot GG, de Groot K. Behavior of fetal rat osteoblasts cultured in vitro on bioactive glass and nonreactive glasses. Biomaterials 1992;13:382-392.

14. Nunes SP, Inoue T. Evidence for spinodal decomposition and nucleation and growth mechanisms during membrane formation. J Membrane Sci 1996;111:93-103.

15. Bulte AMW, Folkers B, Mulder MHV, Smolders CA. Membranes of semicrystalline aliphatic polyamide nylon 4,6: Formation by diffusion-induced phase separation. J Appl Polym Sci 1993;50:13-26.

16. Young TH, Lai JY, Yu WM, Cheng LP. Equilibrium phase behavior of the membrane forming water-DMSO-EVAL copolymer system. J Membrane Sci 1997;128:55-65.

17. Rajaraman R, Rounds DE, Yen SPS, Rembaum A. A scanning electron microscope study of cell adhesion and spreading in vitro. Exp Cell Res 1974;88:327-339. 